\title{
On visual access to letter case and lexical/semantic information
}

\author{
LLOYD L. AVANT \\ Iowa State University, Ames, lowa \\ and \\ ALICE A. THIEMAN \\ Wartburg College, Waverly, Iowa
}

\begin{abstract}
Four experiments were designed to investigate automatic processing of letter case and lexical/semantic information under forward and backward masking conditions that disallowed a visible image. Stimulus displays were letter string pairs; the letter case for each pair matched or mismatched, and the relationship between the two strings within pairs varied. Experiment 1 required direct Same-Different responses to stimulus pairs, and the results indicate that tasks requiring direct responses to stimulus inputs cannot distinguish between conscious response biases and unconscious use of information. Experiments 2 and 3 employed an indirect index of automatic prerecognition analyses of verbal-linguistic parameters and showed that, with $30-\mathrm{msec}$ pre- and postmasked presentations, letter case, orthographic regularity, and lexical/semantic information are all analyzed in unconscious operations. Experiment 4 demonstrated that, under the viewing conditions of Experiments 2 and 3, subjects had no awareness of the stimulus input.
\end{abstract}

Results of several recent studies indicate that subjects access the meaning of words under central masking conditions that deny a visible image of letters in a display (e.g., Balota, 1983; Fowler, Wolford, Slade, \& Tassinary, 1981; Friedman, 1980; Huber \& Johnson, 1980; Marcel, 1980, 1983b; Marcel \& Patterson, 1978). Unless these results can be shown to be artifactual and/or fail to gain converging support from other methods for studying the earliest operations of visual processing, they have important implications for theoretical accounts of (1) the means by which semantic access occurs, (2) the function performed by central pattern masking, and (3) the distinction between visual, but not visible, operations and the outcomes of those operations that constitute current perceptual awareness.

Direct and indirect measures of processing have provided at least partial converging evidence of prerecognition semantic access. Fowler et al. (1981), Friedman (1980), Huber and Johnson (1980), and Marcel (1983b; Marcel \& Patterson, 1978) used procedures that required direct responses to stimulus inputs. Marcel's (1983b; Marcel \& Patterson, 1978) data are the most surprising and counterintuitive. When he determined the longest onset asynchrony between a stimulus and a following pattern mask (SOA) at which subjects made chance-level judgments (defined as .60 probability of correct response),

Portions of these data were reported at the meeting of the Midwestern Psychological Association, Chicago, May, 1983. The authors express appreciation to Paul Koch, Chris Conzemius, and Angela Hemmer for assistance in conducting the experiments, and to Roberta Klatzky, David Balota, and three anonymous reviewers for critical comments on an earlier draft of this paper. Address reprint requests to L. L. Avant, Department of Psychology, Iowa State University, Ames, IA 50011.
Marcel found that the SOA for judgments of semantic similarity between a masked word and two unmasked words was lower than that for judgments of form similarity between the masked and unmasked words which was, in turn, lower than that for presence/absence judgments for the masked word. Marcel's subjects appeared to be sensitive to word meanings at SOAs that denied access to form information, and form information appeared to be available when subjects could not make presence/absence judgments. When Fowler et al. (1981) attempted to replicate Marcel's results, SOAs proved to be too low (between 10 and $20 \mathrm{msec}$ across subjects) to permit an exact replication. Accordingly, Fowler et al. modified the procedure and, at detection-level SOAs (.60 probability of correct response), subjects judged which of two unmasked words was graphically, phonemically, or semantically more similar to the masked word. Accuracy was higher for semantic than for graphic or phonemic judgments, which did not differ, and this result essentially replicated Marcel's major finding.

Huber and Johnson (1980) used a similar procedure and reached a similar conclusion. They presented word, nonword, or word/nonword pairs, one typed above the other, in which letter cases for the pair matched or mismatched. Over practice trials, exposure durations were reduced until each subject reached $50 \%$ correct on Same-Different letter case judgments. On the following test trials at that exposure duration, letter case decisions remained at chance level, but lexical status decisions were a statistically significant $7 \%$ above chance level. Assuming that chancelevel letter case decisions indicate absence of a visible image of the display, these results also indicate lexical access without a visible display. 
Friedman (1980) asked subjects for letter identity and case reports for single-letter and four-letter pseudoword displays presented at pre- and postmasked exposure durations that produced .50 probability of correct response. For correctly identified letters, case reports (adjusted for guessing) were incorrect for $14 \%$ of the single letters and for $50 \%$ of the pseudowords (Experiment 1). This predominance of identity information over case information held for different type fonts, when letters were of different sizes, and when task instructions emphasized correct case reports.

However, unambiguous interpretation of direct measures of apparently unconscious lexical/semantic access is difficult. Nolan and Caramazza (1982) reported a failure to replicate Marcel's finding. Also, Fowler et al. (1981) conducted a control experiment that cast doubt on their data as indicating semantic access prior to form analysis. Moreover, Merikle (1982) recently pointed out that, in order for a forced-choice procedure to establish an exposure duration at which unconscious, but not conscious, perception may occur, it is necessary to (1) show that each subject uses both response options and (2) determine whether the observed stimulus-response correlations for the two responses differ from those expected by chance. Merikle's threshold criteria were not met by Marcel, by Fowler et al., or by Huber and Johnson.

Because they also distrusted direct responses to stimuli that subjects claimed not to have seen, Marcel and Fowler et al. complemented their direct measures with indirect measures. Both Marcel and Fowler et al. used the priming task to test effects of a prime stimulus masked at detection-level SOAs. Marcel found essentially the same facilitation of lexical decisions from semantically related primes when they were unmasked $(62 \mathrm{msec})$ as when they were dichoptically masked at detection-level SOAs $(56 \mathrm{msec})$. Fowler et al. tested priming effects of the phonemic/graphemic, as well as semantic, relationship between prime and target. For both unmasked and dichoptically masked primes, semantic relatedness facilitated, and phonemic/graphemic relatedness interfered with, both reaction time and response accuracy. Also, reaction time for masked primes was marginally faster $(23 \mathrm{msec}, \mathrm{p}=$ $.07)$ than for unmasked primes. Balota (1983) determined exposure durations for masked primes that met Merikle's (1982) criteria for distinguishing between conscious and unconscious processing and confirmed Fowler et al.'s finding of faster reaction time for masked than for unmasked primes $(31 \mathrm{msec}, \mathrm{p}<.01)$. The faster response for primes masked dichoptically at detection-level SOAs than for unmasked primes suggests that the conscious lexical decision process was easier for the subject when it was not encumbered by conscious residuals of the visual, but not visible, operations that were initiated by registration of the prime.

In the present study, we followed the strategy of combining a direct and an indirect measure of processing to test whether lexical/semantic access can occur in the absence of visible letter case information. In Experiment 1, we used a version of Huber and Johnson's Same-Different direct measure. We modified the task to apply Merikle's (1982) criteria for distinguishing between unconscious and conscious perception in determining, for each subject, an exposure duration for pre- and postmasked inputs at which Same-Different letter case decisions reached chance level. In three following sessions, subjects were tested on meaning, lexical, and case decisions. To obtain an indirect measure of early processing in Experiments 2 and 3, we used the duration judgment task previously reported from our laboratory (Avant, Bartsch, \& Woods, 1977; Avant \& Lyman, 1975; Avant, Lyman, \& Antes, 1975; Avant, Lyman, Skowronski, \& Millspaugh, 1977; Avant, Mineck, \& Favale, 1984). Unlike procedures that direct the subject to attend to and process verbal-linguistic parameters of the input, the duration judgment task tests effects of manipulating verbal-linguistic parameters when the task requirement is to process temporal rather than verbal information. The procedure will be described in the introduction to Experiment 2. Experiment 4 was designed to test recognizability of stimulus inputs under the viewing conditions of Experiments 2 and 3.

\section{EXPERIMENT 1}

Experiment 1 was designed to test replicability of Huber and Johnson's result and extend that study in a modification of the procedure which (a) used a considerably more rigorous determination of the exposure duration for chance level letter case discriminations, (b) varied the relationship between members of the letter string pairs, and (c) asked for Same-Different meaning decisions as well as case and lexical decisions. The expectation from Huber and Johnson's study was that lexical decisions could be made at exposure durations that produce chance-level letter case discrimination; Marcel's, Fowler et al.'s, and Balota's priming studies suggest that these viewing conditions might also permit Same-Different meaning decisions.

\section{Method}

Subjects. Forty volunteers from undergraduate psychology courses at Iowa State University received course credit for participation. Ten served in each of four groups. All had normal or corrected-to-normal vision.

Stimulus materials. Stimuli were pairs of letter strings, one typed above the other. Stimulus pairs were two words, two nonwords, or a word and a nonword. In an effort to maximize encodability of these materials, words were selected from Snodgrass and Vanderwart's (1980) norms to be high imageability nouns which were examplars from six conceptual categories (furniture, body parts, weapons, tools, apparel, and vehicles). Nonwords were anagrams of the words, with letters sequenced to obtain low spatial frequency redundancies by Mayzner and Tresselt's (1965) single-letter norms. Table 1 presents examples of the stimulus pairs and shows the six relationships between the members of respective pairs. Four exemplars were selected from each of the six conceptual categories for the Word Match (WM) condition of Table 1; the other relationships between letter string pairs were derived from that condition. As Table 1 shows, those six relationships were presented in both matching and mismatching letter case pairs. Table 1 also shows 
Table 1

Illustrative Stimulus Pairs: Experiment 1.

Relationships Between Paired Letter Strings

\begin{tabular}{|c|c|c|c|c|}
\hline \multirow{2}{*}{ Relationship } & \multirow[b]{2}{*}{ Stimulus Pair } & \multicolumn{3}{|c|}{ Correct Response For Each Task } \\
\hline & & Case Task & Meaning Task & Lexical Task \\
\hline Matching Case & BED & & & \\
\hline WM: Word Match & BED & Same & Same & Same \\
\hline SM-Synonym Match & $\begin{array}{l}\text { BED } \\
\text { BUNK }\end{array}$ & Same & Same & Same \\
\hline & BED & & & \\
\hline WMM: Word Mismatch & STEED & Same & Different & \\
\hline W/NMM: Word/Nonword Mismatch & $\begin{array}{l}\text { BED } \\
\text { EESTD }\end{array}$ & Same & Different & Different \\
\hline NM: Nonword Match & $\begin{array}{l}\text { EDB } \\
\text { EDB }\end{array}$ & Same & Same & Same \\
\hline N/NMM: Nonword/Nonword Mismatch & $\begin{array}{l}\text { EDB } \\
\text { EESTD }\end{array}$ & Same & Different & \\
\hline Mismatching Case & BED & & & \\
\hline Wm: Word Match & bed & Different & Same & Same \\
\hline Sm: Synonym Match & $\begin{array}{l}\text { BED } \\
\text { bunk }\end{array}$ & Different & Same & Same \\
\hline Wmm: Word Mismatch & $\begin{array}{l}\text { BED } \\
\text { steed }\end{array}$ & Different & Different & \\
\hline W/Nmm: Word/Nonword Mismatch & $\begin{array}{l}\text { BED } \\
\text { eestd }\end{array}$ & Different & Different & Different \\
\hline Nm: Nonword Match & $\begin{array}{l}\text { EDB } \\
\text { edb }\end{array}$ & Different & Same & Same \\
\hline N/Nmm: Nonword/Nonword Mismatch & $\begin{array}{l}\text { EDB } \\
\text { eestd }\end{array}$ & Different & Different & \\
\hline
\end{tabular}

the response scored as correct for each of the 12 combinations of six relationships and matching versus mismatching letter case in the case, meaning, and lexical decision tasks. Letter strings were typed on mylar plastic and mounted in $2 \times 2$-in. slides for presentation in a Scientific Prototype Model GB tachistoscope. Strings ranged from three to seven letters in length; vertical visual angle for the pair was $1^{\circ} 53^{\prime}$, and horizontal visual angles ranged from $1^{\circ} 19^{\prime}$ to $3^{\circ} 18^{\prime}$. A pattern mask contained five rows of 13 overlaid $\mathrm{Xs}$ and $0 \mathrm{~s}$ in which the middle $\mathrm{X}$ was omitted to provide a fixation point; vertical and horizontal visual angles were $2^{\circ} 26^{\prime}$ and $5^{\circ} 57^{\prime}$ respectively. The light level for each field of the tachistoscope was adjusted to $58.21 \mathrm{~cd} / \mathrm{m}^{2}$ with no stimulus in the field. The mask slide provided the adaptation field, and stimulus presentations were essentially interruptions of that field to provide both forward and backward masking of each stimulus pair.

To prevent subjects from adopting a strategy of basing the SameDifferent decision on a single letter in each row, the arrangement of mismatching case pairs was varied. With the four exemplars from each conceptual category, four stimulus sets were defined by the arrangement of matching versus mismatching letter case in stimulus pairs. As can be seen in Table 2, mismatching case pairs presented the same letter case for all letters within a string for two stimulus sets and, for two sets, only one letter in one string mismatched all others.

Procedure and design. Separate sessions were conducted for each of the four tasks. The first session was used to determine, for each subject, the exposure duration for criterion-level performance on letter case discriminations. For this task, exposure durations began at 110 -msec presentations of stimuli from each of the 12 conditions illustrated in Table 1. Exposure duration was lowered by 10 -msec steps across independently randomized replications of the 12 inputs until the first replication for which the subject's proba- bility of correct response was at or below .50. Then the amount by which the exposure duration was changed for each additional replication was adjusted to each subject's performance until five replications were obtained that met the following two criteria: (1) for three of the replications, probability of correct Same-Different case decisions had to be no better than .50; and (2) for the other two replications, probability of correct Same-Different case decisions had to be 60 or better at an exposure duration $10 \mathrm{msec}$ above the duration that produced the three replications at chance-level discriminations. These two criteria were imposed with the intent of establishing an exposure duration that produced chance-level performance but was not so far below a discrimination threshold that essentially no information could be extracted during the presentation.

Also, for the three replications that indicated chance-level performance, Merikle's (1982) two criteria for unconscious, but not conscious, perception were applied. To assure that both Same and Different responses were used on the 36 trials of the three critical replications, a $99 \%$ confidence interval was computed about a proportion of .50 (10 to 26 responses), and subjects whose use of

Table 2

Stimulus Sets: Experiment 1

\begin{tabular}{|c|c|c|c|}
\hline Set 1 & Set 2 & Set 3 & Set 4 \\
\hline \multicolumn{4}{|c|}{ Matching Case } \\
\hline $\begin{array}{l}\text { CHAIR } \\
\text { CHAIR }\end{array}$ & $\begin{array}{l}\text { chair } \\
\text { chair }\end{array}$ & $\begin{array}{l}\text { CHAIR } \\
\text { CHAIR }\end{array}$ & $\begin{array}{l}\text { chair } \\
\text { chair }\end{array}$ \\
\hline \multicolumn{4}{|c|}{ Mismatching Case } \\
\hline $\begin{array}{l}\text { CHAIR } \\
\text { chair }\end{array}$ & $\begin{array}{l}\text { CHAIR } \\
\text { chair }\end{array}$ & $\begin{array}{l}\text { CHAIR } \\
\text { CHaIR }\end{array}$ & $\begin{array}{l}\text { chair } \\
\text { chAir }\end{array}$ \\
\hline
\end{tabular}


either response exceeded that interval were excluded. Also, to assure that the critical exposure duration did not permit awareness of the letter features of the display, a chi-square test of relatedness between Matching-Mismatching letter case pairs and the use of Same-Different responses was computed for each subject. Any subject for whom the chi-square showed a significant relationship between type of stimulus and type of response was excluded. Eight subjects were excluded by applying Merikle's two criteria.

With each subject's exposure duration set in the first session, the other three sessions were used to test differences among case, lexical, and meaning decisions. The four stimulus sets illustrated in Table 2 were constructed with different words (and their anagrams) from the six conceptual categories. Those stimulus sets were counterbalanced across the four tasks, so subjects performed each task with a different stimulus set. The order of case, meaning, and lexical decision tasks in sessions 2,3 , and 4 was varied across subjects to avoid confounding by practice effects.

The design tested subjects over six replications of the 12 types of letter string pairs in the case and meaning decision tasks; the number of correct Same and Different responses was equated for both tasks. To equate the number of correct Same and Different responses for the lexical decision task (see Table 1), the WMM, $\mathrm{N} / \mathrm{NMM}, \mathrm{Wmm}$, and N/Nmm conditions (Same) were deleted, and the W/NM and W/Nm conditions (Different) were presented three times in each replication while the WM, SM, NM, Wm, Sm, and $\mathrm{Nm}$ conditions (Same) were each presented once. The performance measure was proportion of correct responses for each condition over the six replications.

The design permitted, first, a test of the effect of stimulus sets on exposure durations producing chance-level case discriminations in the first session, and then independent tests of the effects of stimulus set and the relationship between members of stimulus pairs on the following case, lexical, and meaning decision tasks. Task order was considered a control manipulation and was not statistically evaluated.

\section{Results}

The threshold setting task. Across subjects, exposure durations for chance-level case discriminations in the first session ranged from $10-80 \mathrm{msec}$ and averaged $41 \mathrm{msec}$. Mean durations for sets 1 to 4 were $40,46,35$, and 42 $\mathrm{msec}$ respectively, and analysis of variance showed no differences among sets $(F<1.00)$.

The overall analysis. An overall analysis excluded the first session and evaluated stimulus sets (with subjects nested within sets), tasks (case, meaning, lexical), and the 12 conditions for the respective tasks. The analysis showed a significant main effect of conditions within tasks $[F(11,396)=8.28, p<.001]$. This main effect collapses across the response requirements of the three tasks for the various conditions and shows that proportions of correct responses were higher for conditions that required a Same response in at least two of the tasks (conditions WM, SM, NM, Wm, Sm, and Nm for which mean proportion correct $=.56$ ) than for conditions that required a Different response in at least two of the tasks (conditions W/NM, Wmm, W/Nm, and N/Nmm for which mean proportion correct $=.45$ ).

The analysis also revealed a significant interaction between tasks and conditions within tasks $[F(22,792)=$ $5.18, \mathrm{p}<.0001]$. Mean proportions of correct responses for each condition for each task are presented in Table 3.

Analyses for each task. The tasks $\times$ conditions interaction was pursued in three analyses that evaluated stimu-
Table 3

Mean Proportions of Correct Responses for Each Stimulus Pair Relationship in Experiment 1

Word/ Nonword/

Word Synonym Word Nonword Nonword Nonword

Task Match Match Mismatch Mismatch Match Mismatch
Matching Case Conditions

\begin{tabular}{lcccccc} 
Case & .52 & .59 & .57 & .61 & .57 & .56 \\
Meaning & .55 & .57 & .41 & .41 & .55 & .47 \\
Lexical & .63 & .66 & \multicolumn{5}{c}{ Mismatching Case Conditions } \\
& \multicolumn{7}{c}{.40} & .60 & \\
Case & .41 & .43 & .43 & .45 & .44 & .42 \\
Meaning & .58 & .58 & .44 & .48 & .59 & .52 \\
Lexical & .60 & .63 & & .40 & .61 & \\
\hline
\end{tabular}

lus sets and conditions for each task separately. Stimulus sets had a significant effect in only the case decision task $[\mathrm{F}(3,36)=4.55, \mathrm{p}<.008]$. Mean proportions of correct responses for sets 1 to 4 were $.52, .45, .54$, and .49 respectively. Simple main effect tests showed no effect of having all letters in each of the two rows mismatch versus having a single letter in one row mismatch all others. Instead, the significant difference was for pairs in which all letters within a row were of the same case; probability of correct response was higher for matching than for mismatching pairs when matching pairs were upper case $[F(11,396)=5.06, p<.05]$, but not when the matching pairs were lower case. This result shows that subjects did not base their Same-Different decision on a single letter in each row.

The main effect of the 12 conditions was significant in the case, meaning, and lexical decision tasks $[F(11,396)$ $=5.06, \mathrm{p}<.001 ; 3.70, \mathrm{p}<.001$; and 9.46, $\mathrm{p}<.001$, respectively]. Planned comparisons evaluated case, meaning, and lexical judgments in each of the three tasks. For the case task, the effect of matching versus mismatching letter case was highly significant $[F(1,396)=50.38, p$ $<.0001]$. For the meaning decision task, the effect of matching versus mismatching meaning was significant $[\mathrm{F}(1,396)=32.47, \mathrm{p}<.001]$. And, for the lexical decision task, the effect of matching versus mismatching lexical status was significant $[F(1,396)=100.40, \mathrm{p}<$ $.0001]$. None of the other planned comparisons was significant.

For each task then, the planned comparisons showed a significant effect of the type of information required by the task, but no influence of the other two types of information. But this factor also defines the Same-Different response for each task. Thus, the observed effects may simply reflect the fact that, for each task, Same responses were more frequently correct than Different responses.

\section{Discussion}

These results highlight a methodological problem that disallows an unambiguous interpretation of the data. Merikle's two criteria for setting a threshold exposure duration capable of distinguishing between unconscious and conscious processing were met for each subject in the first session of this experiment. The problem is that properly 
setting a threshold exposure duration does not assure that the tests which follow that procedure will distinguish between apparently unconscious processing of information and conscious response biases. This is a particularly pernicious problem for tasks that require a direct forcedchoice response to stimulus inputs. Results of Experiment 1 exemplify the problem. The pattern of significant planned comparisons is consistent with the hypothesis that, for the case, meaning, and lexical decision tasks, subjects selectively extracted case, meaning, or lexical information to meet task requirements. However, the fact that, for each task, the relevant information processing variable was confounded with the response requirement means that a bias favoring Same responses cannot be separated from selective use of case, meaning, and lexical information. Arguments against the response bias hypothesis could be offered (Marcel, 1983a, has offered one cogent argument), but the empirical data fail to make the distinction clear.

Because Experiment 1 did not produce a pattern of results that unequivocally discriminates between unconscious processing and potential response biases, we, like Marcel (1983b) and Fowler et al. (1981), turned to an indirect measure of processing. For Experiments 2 and 3 we adopted a duration judgment paradigm that was developed in our laboratory. The task presents a situation unlike others in which verbal infornation is processed; its uniqueness permits it to reveal unconscious mental operations when subjects are not asked to deal directly with verbal/linguistic parameters. The paradigm presents trials on which two pre- and postmasked stimulus presentations are separated by $1 \mathrm{sec}$, and the subject's task is to judge which of the two equal clock-time presentations is of longer apparent duration. Thus, subjects are never asked for a direct response to any stimulus, and stimulus presentations appear as two interruptions in the subject's viewing of the mask. With both forward and backward masking, the subject is not aware of a visible image of either stimulus presentation. For each trial, the subject simply reports "first" or "second," depending on which of the paired flashes appears to be longer. Randomized orders for the sequence of trials as well as for orders of presenting each stimulus as the first or second stimulus on a given trial prevent attachment of a response bias in the use of "first" versus "second" to any parameter of the stimulus set. Subjects whose use of either response option exceeds a $99 \%$ confidence interval around a proportion of .50 are excluded.

Results of previous uses of the paradigm particularly recommend it for investigating the earliest operations in visual processing (e.g., Avant, Bartsch, \& Woods, 1977; Avant \& Lyman, 1975; Avant, Lyman, \& Antes, 1975; Avant, Lyman, Skowronski, \& Millspaugh, 1977; Avant, Mineck \& Favale, 1984). For example, when an unfamiliar nonword (EIO), a familiar word (DIG), and a more familiar single letter (I) were presented for $30 \mathrm{msec}$ and judged against each other, duration judgments ranked them nonword $>$ word $>$ single letter. Moreover, com- parison of judgments for these stimuli when they were not masked (and stimuli were recognizable) versus when they were both pre- and postmasked (and stimuli were not recognizable) showed that (a) the differences in apparent duration among stimuli were greater under the masked than under the unmasked condition, and (b) subjective differences in perceived duration were apparently easier to discriminate under the masked condition; at least decision latencies were lower under the masked condition (Avant et al., 1975).

We believe that these results, and confirming findings from our other studies, conform most parsimoniously to the following interpretation. The task requires a comparison between the apparent durations of two perceptual events that must be individually marked. Given that a pattern mask is presented in clear vision except during the two tachistoscopic flashes of each trial, the following sequence of events would be expected before the subject could make a discriminative judgment at the end of the trial. The subject would (1) clearly see the mask at the beginning of the trial, (2) intake and incompletely analyze the first stimulus, (3) mark the end of the first perceptual event with the immediately following onset of the mask and store the results of the first incomplete analysis while seeing and consciously processing the mask during the 1,000-msec interval separating stimulus inputs, (4) intake and incompletely analyze the second stimulus input, (5) mark the end of the second perceptual event with the return of the mask and store the results of the second incomplete analysis, and (6) compare the results of the two incomplete analyses to determine the duration judgment while the mask is in view after the second stimulus. Because clock-time is the same for both stimulus presentations and the pattern mask occupies the visual system except for those two intervals, the relative judgment for the two intervals must directly depend on stored information extracted during the stimulus intervals. Unless the results of those abbreviated analyses were available at the time of the duration decision, those decisions could not be differentially influenced by stimulus parameters.

If this view of the sequence of events is correct, then duration judgments from this paradigm reflect both a rudimentary analysis of each stimulus input and a brief (perhaps no longer than 2-sec) storage of the results of the incomplete analyses. Results of our previous studies indicate that subjective duration judgments are influenced by the subject's familiarity with verbal materials. This finding suggests that such judgments are based on the output or record of abbreviated analyses. The fact that our previous results have shown an inverse relationship between judged durations and stimulus familiarity may mean that such judgments are based on the amount of information recovered from or some record of the analysis per se (e.g., duration or difficulty). It is also noteworthy that the $\mathrm{z}^{\prime}$ measure from this paradigm is sensitive to the cognitive distinctions among a nonword, word, and single letter under the same conditions for which the $\mathrm{d}^{\prime}$ of signal detection theory discriminates only the stimulus size 
difference between the larger area of the two three-letter stimuli and the smaller area of the single letter (Avant, Bartsch, \& Woods, 1977). The most succinct summary of the unique contribution from this paradigm is by Turvey (1978, p. 129), who noted that, in this paradigm, apparent duration of the flashes " is reflective of what has been done and serves to distinguish between orders of processing that remain incomplete."

\section{EXPERIMENT 2}

In Experiment 2, we used the paradigm to test effects of matching versus mismatching letter case and lexical status of letter string pairs. Specifically, subjects judged which of two stimulus presentations-each stimulus a letter string pair-was longer in duration. Because previous uses of the paradigm have shown that pre- and postmasked 30-msec presentations initiate processing without permitting recognition, that duration was used in Experiment 2. It should be noted that this duration is $11 \mathrm{msec}$ less than the average exposure duration that produced performance meeting Merikle's criteria for chance-level letter case discriminations in the first session of Experiment 1. Given the previous evidence that the paradigm is sensitive to the cognitive distinction between words and nonwords, we expected briefer apparent durations for word pairs than for nonword pairs; previous data did not provide an expectation for apparent durations for word/nonword pairs relative to word pairs and nonword pairs. No expectations were specified for effects of the letter case manipulation.

\section{Method}

Subjects. Two groups of 40 volunteers from undergraduate courses participated for course credit; all subjects had normal or corrected-to-normal vision.

Stimulus materials. Stimulus materials were a subset of those from Experiment 1. Each stimulus was a pair of words, nonwords, or a word/nonword pair. The two members of a pair were of matching or mismatching letter case. Matching letter case pairs were upper case for one group of subjects and lower case for the other; for both groups of subjects, mismatching pairs presented one letter string in upper case and the other in lower case. This arrangement of matching and mismatching pairs was selected because the results of Experiment 1 showed (a) that there was no effect of the four stimulus set arrangements on exposure durations for chance-level performance, and (b) that the differential effect of matching versus mismatching letter case in the case decision task occurred only for pairs in which all letters in a row were of the same case. The paradigm and the stimulus materials are illustrated in Figure 1. Eight sets of pairs were selected for the six combinations of letter case (2) and lexical status (3); four exemplars of the furniture and weapons categories provided the eight word/word pairs, and the word/nonword and nonword/nonword pairs were derived from them. The pattern mask and light levels of the tachistoscope were the same as for Experiment 1 .

Procedure and design. All possible combinations of lexical status and letter case, except for identical pairs, were tested. There were thus $6(5) / 2=15$ types of pair comparisons such that each stimulus was paired with and judged against every other member of the set. Subjects were presented four replications of those 15
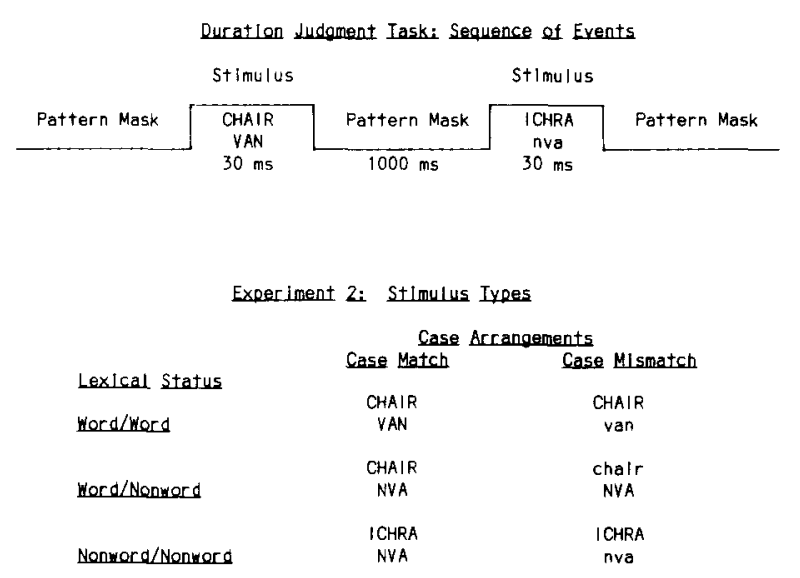

Figure 1. Sequence of events in the duration judgment paradigm and illustrative stimuli for Experiment 2.

comparisons; order of presentation of the comparisons was independently randomized for each replication for each subject. A z' score (Woodworth \& Schlosberg, 1954) for each stimulus was computed from the average number of "longer" responses given that stimulus across the four replications.

\section{Results and Discussion}

The design evaluated two between-subjects factors: group (defined by the case of paired items in the matched case stimulus) and stimulus exemplars; the two withinsubjects factors were letter case arrangement (match vs. mismatch) and lexical status (word/word, word/nonword, or nonword/nonword).

The analysis of $z^{\prime}$ scores did not confirm the simple expectation that word/word presentations would be judged briefer than nonword/nonword presentations; the main effect of lexical status was not significant $(\mathrm{F}<1.00)$. More important was the evidence that both letter case and lexical information were being analyzed. The analysis revealed two significant sources of variance. One was the lexical status $\times$ letter case arrangement interaction $[F(2,128)=5.46, p<.005]$. The other was the interaction between groups and lexical status $[F(2,128)=3.62$, $\mathrm{p}<.05]$. Simple main effect tests within the lexical status $\times$ letter case arrangement interaction showed significant differences among apparent durations for word/word, word/nonword, and nonword/nonword pairs when letter case for the pair matched $[\mathrm{F}(2,128)=4.02, \mathrm{p}<.05]$, but not when letter cases mismatched $[\mathrm{F}(2,128)=$ $2.51, \mathrm{p}>.05]$. For matching case pairs, the NeumanKeuls test $(\alpha=.05)$ showed the mean $\mathrm{z}^{\prime}$ score for word/word pairs $(-.06)$ to be significantly lower than that for nonword/nonword pairs (.05), but the intermediate mean $z^{\prime}$ score for word/nonword pairs (.01) did not differ from that for either word/word or nonword/nonword pairs.

The lexical status $\times$ groups interaction supplemented the information from the interaction between lexical status and letter case arrangement. The interaction showed significant differences among mean $z^{\prime}$ scores for 
Table 4

Mean Proportions of "Longer" Responses in Experiment 2

\begin{tabular}{lccc} 
& \multicolumn{2}{c}{ Matching Pairs } & \\
\cline { 2 - 3 } & Upper Case & Lower Case & Mean \\
\hline & Matching Case & & \\
Word/Word & .49 & .47 & .48 \\
Word/Nonword & .52 & .49 & .51 \\
Nonword/Nonword & .51 & .53 & .52 \\
& & & \\
Mord/Word & .51 & .53 & .52 \\
Word/Nonword & .50 & .46 & .48 \\
Nonword/Nonword & .49 & .52 & .51 \\
\hline
\end{tabular}

word/word (-.01), word/nonword (-.06), and nonword/nonword pairs $(.07)$ for subjects presented lower case matching pairs $[\mathrm{F}(2,128)=3.74, \mathrm{p}<.05]$, but not for subjects presented upper case matching pairs $(\mathrm{F}<$ $1.00)$.

The $z^{\prime}$ scores that revealed these effects are derived measures of the relative apparent durations for the various stimuli within a set. The magnitude of the interactive effects of lexical status and letter case arrangement are perhaps clearer in the proportions of "longer" judgments given each type of stimulus pair that are presented in Table 4.

These results are consistent with those from earlier studies using this paradigm. If the sequence of events on each trial forces the duration judgment to reflect effects of information extracted during each flash, then these results suggest that (a) either the representational formats for lexical status and letter case information are different in earliest processing, and/or (b) the operations that use the two types of information are different. If the effect of lexical status must be mediated by prior partial analysis of letter case information, then these data show that sufficient letter feature information can be extracted within $30 \mathrm{msec}$ to permit access to and use of lexical information, even if the subject has no visible image of the input. Otherwise, the data suggest simultaneous access to letter case and lexical information. In any case, the data show that both types of information can jointly influence a conscious decision process when viewing conditions deny the subject a visible image of the display.

\section{EXPERIMENT 3}

Experiment 3 addressed two questions left unanswered by the results of Experiment 2 .

First, the effect of the lexical status manipulation in Experiment 2 could have been produced by the orthographic structure of the letter strings rather than access to lexical knowledge. There is considerable evidence that orthographic structure influences early visual processing independently of the meaning or lexical status of the input (e.g., Baron, 1975; Baron \& Thurston, 1973; Estes, Allmeyer, \& Reder, 1976; Hirata \& Bryden, 1971; Massaro, 1973, 1975; Mason, 1975; Venesky, 1967, 1970; Venesky \& Massaro, 1979). However, the results of Experiment 2 suggest that, if effects of lexical status and or- thographic regularity can be separated in this task by testing words, orthographically regular pseudowords, and orthographically irregular nonwords in Experiment 3, the result should show apparent durations to rank them words $<$ pseudowords < nonwords.

Second, Haber's (1969) report that repeated brief presentations of stimuli increased their "perceptual clarity" suggests that, across the four replications of Experiment 2 , the processing of our stimuli may have changed if they became more nearly recognizable.

Accordingly, Experiment 3 was designed to test effects of (1) orthographic regularity versus lexical status and (2) replications.

\section{Method}

Subjects. Thirty-two students from undergraduate psychology courses at Wartburg College participated for course credit. All subjects had normal or corrected-to-normal vision.

Stimulus materials. Stimuli were word/word, pseudoword/pseudoword, and nonword/nonword pairs, typed one above the other. Letter strings were five- and six-letter strings with visual angles matching those in the first two experiments. Four different pairs of words were selected from the materials of Experiment 1. The criteria imposed for the pseudoword/pseudoword pairs guided selection of words for the word/word pairs. Pseudowords were intended to be meaningless but of legal orthographic structure. Orthographic regularity has been variously defined, and no comprehensive set of rules for defining orthographic regularity exists (see Venesky \& Massaro, 1979). The constraints on the words selected for the experiment were that they contain at least two consonants and two vowels. These constraints permitted generation of two sets of pseudoword anagrams of the words by changing the order of the vowels for one set and changing the order of the consonants for the other set. The assurance that the orthographic structure of the pseudowords was legal in English usage was that, for each pseudoword, Webster's New Collegiate Dictionary (1973) contains at least one word that begins with the same sequence of three letters and another word that ends with the same sequence of three letters. Nonwords were also anagrams of the words, with letters sequenced to obtain low spatial frequency redundancies by Mayzner and Tresselt's (1965) norms. Thus, there were four pairs of words and, for each word pair, a pair of pseudowords in which the order of the vowels in the words was changed, a pair of pseudowords in which the order of the word consonants was changed, and a pair of nonwords with illegal orthographic structure. As illustrated in Table 5, these materials were typed in upper case matching, lower case matching, and upper/lower case mismatching pairs.

Procedure and design. A six-member stimulus set was used for each subject. Each set contained matching and mismatching letter

Table 5

Illustrative Stimulus Pairs: Experiment 3

\begin{tabular}{|c|c|c|c|}
\hline \multirow[b]{2}{*}{ Word } & \multicolumn{2}{|c|}{ Pseudoword } & \multirow[b]{2}{*}{ Nonword } \\
\hline & Vowel Change & Consonant Change & \\
\hline \multicolumn{4}{|c|}{$\begin{array}{c}\text { Matching Case } \\
\text { Upper }\end{array}$} \\
\hline CHAIR & CHIAR & RAICH & ICHRA \\
\hline BOVINE & BEVONI & NOBIVE & NVEBIO \\
\hline \multicolumn{4}{|c|}{ Lower } \\
\hline $\begin{array}{l}\text { chair } \\
\text { bovine }\end{array}$ & $\begin{array}{l}\text { chiar } \\
\text { bevoni }\end{array}$ & $\begin{array}{l}\text { raich } \\
\text { nobive }\end{array}$ & $\begin{array}{l}\text { ichra } \\
\text { nvebio }\end{array}$ \\
\hline \multicolumn{4}{|c|}{ Mismatching Case } \\
\hline $\begin{array}{l}\text { CHAIR } \\
\text { bovine }\end{array}$ & $\begin{array}{l}\text { chiar } \\
\text { BEVONI }\end{array}$ & $\begin{array}{l}\text { RAICH } \\
\text { nobive }\end{array}$ & $\begin{array}{l}\text { ichra } \\
\text { NVEBIO }\end{array}$ \\
\hline
\end{tabular}


case versions of a word/word, pseudoword/pseudoword, and nonword/nonword pair. For half the subjects, pseudoword pairs were those produced by changing the order of word vowels and, for the remaining subjects, pseudowords were those produced by changing the order of the word consonants. Also, for half the subjects, matching letter case pairs were upper case and, for the other half, matching case pairs were lower case. The $6(5) / 2=15$ trials of the pair comparisons procedure for the six-member stimulus set was replicated four times with each subject; order of presentations was independently randomized for each replication for each subject, and $\mathrm{z}^{\prime}$ scores were derived from proportions of longer responses given each member of the stimulus set within each of the four replications. Exposure durations were $30 \mathrm{msec}$, and other particulars of the viewing conditions were as described for Experiment 2.

\section{Results}

Two subjects were nested in each of the 16 combinations of the three between-subjects variables (upper vs. lower case matching pairs, vowel vs. consonant change in pseudowords, and the four word exemplars). Replications, lexical status of pairs, and matching versus mismatching letter case pairs were the within-subjects variables.

In the analysis that evaluated effects of all factors, only one source of variance - the main effect of lexical statuswas statistically significant $[F(2,32)=6.19, p<.005]$. Mean $\mathbf{z}^{\prime}$ scores for word, pseudoword, and nonword pairs were $-.08,-.02$, and .09 respectively; presentations of word pairs were judged to be briefer than equal presentations of pseudoword pairs which were, in turn, judged to be briefer than equal presentations of nonword pairs. Although the effect of lexical status was highly significant, the magnitude of the effect was not large. The size of the effect may be judged from the proportions of longer responses for each type of stimulus presented in Table 6 .

These results unambiguously address the two questions of concern in Experiment 3. First, the lack of any effect of replications suggests that, in this task, four replications of the procedure did not modify either (a) the representational formats of the types of information provided in these stimuli or (b) the earliest visual operations applied to that information.

Second, and more important, the observed word < pseudoword < nonword ordering of apparent durations exactly fits the expectation drawn from Experiment 2 . The

Table 6

Mean Proportions of "Longer" Responses in Experiment 3

Matching Pairs

\begin{tabular}{|c|c|c|c|}
\hline & \multicolumn{2}{|c|}{ Matching Pairs } & \multirow[b]{2}{*}{ Mean } \\
\hline & Upper Case & Lower Case & \\
\hline \multicolumn{4}{|c|}{ Matching Case } \\
\hline Words & .44 & .49 & .47 \\
\hline Pseudowords & .50 & .48 & .49 \\
\hline Nonwords & .58 & .55 & .56 \\
\hline \multicolumn{4}{|c|}{ Mismatching Case } \\
\hline Words & .46 & .48 & .47 \\
\hline Pseudowords & .48 & .50 & .49 \\
\hline Nonwords & .53 & .48 & .51 \\
\hline
\end{tabular}

highly significant effect of lexical status suggests (a) that the representational formats for lexical status and orthographic regularity information are not the same, and (b) that the higher, rather than lower, order information has priority in influencing the conscious decision process in this task. The lowest order information in these stimuli (letter case match-mismatch) had no effect that could be statistically verified when independent and joint effects of all variables were evaluated in an overall analysis.

The failure to discern an effect of the letter case manipulation in the analysis discussed above leaves one to wonder how an effect of lexical status can show itself in an automatic activation process without indicating in some way how lexical status was mediated by extraction of letter feature (i.e., case) information. We pursued the effect of letter case match-mismatch by considering that its effect might be obscured across replications of the procedure. Accordingly, in a second analysis of the data we removed the effect of replications by using $z^{\prime}$ scores derived from the average proportion of longer responses given each stimulus across the four replications.

In this analysis, of course, the main effect of lexical status was not affected $[\mathrm{F}(2,32)=6.36, \mathrm{p}<.005]$. However, the four-way interaction among type of matching case pairs (upper vs. lower), type of pseudoword (vowel vs. consonant change), lexical status, and letter case match-mismatch was significant $[\mathrm{F}(2,32)=4.23$, $\mathrm{p}<.05]$. This interaction is summarized graphically in Figure 2. The important contrast is between the left and right panels of the figure. The left panel plots the interaction among lexical status, type of pseudoword, and letter case match-mismatch for subjects presented matching upper case pairs; the right panel plots that interaction for subjects presented lower case matching pairs. Figure 2 illustrates that, when matching case pairs were upper case, three of the four combinations of matching-mismatching letter case and type of pseudoword produced the word $<$ pseudoword < nonword pattern of duration judgments. However, as the right panel of Figure 2 shows, when matching case pairs were lower case, only one of the combinations of matching-mismatching letter case and type of pseudoword produced the word < pseudoword $<$ nonword pattern of duration judgments. The interaction clearly shows that letter feature information did influence processing, because upper versus lower case matching pairs is the only parameter that differs between the panels of Figure 2. The participation of orthographic information (type of pseudoword) in this interaction complements the indication of its influence in the intermediate duration judgment for pseudowords in the lexical status main effect. If the distinction between early analytic operations and subsequent recovery operations is valid (Marcel, 1983a, has presented cogent arguments for the distinction), then the interaction plotted in Figure 2 may well reflect an analytic process that utilized letter case, orthographic, and semantic information, perhaps simultaneously. 


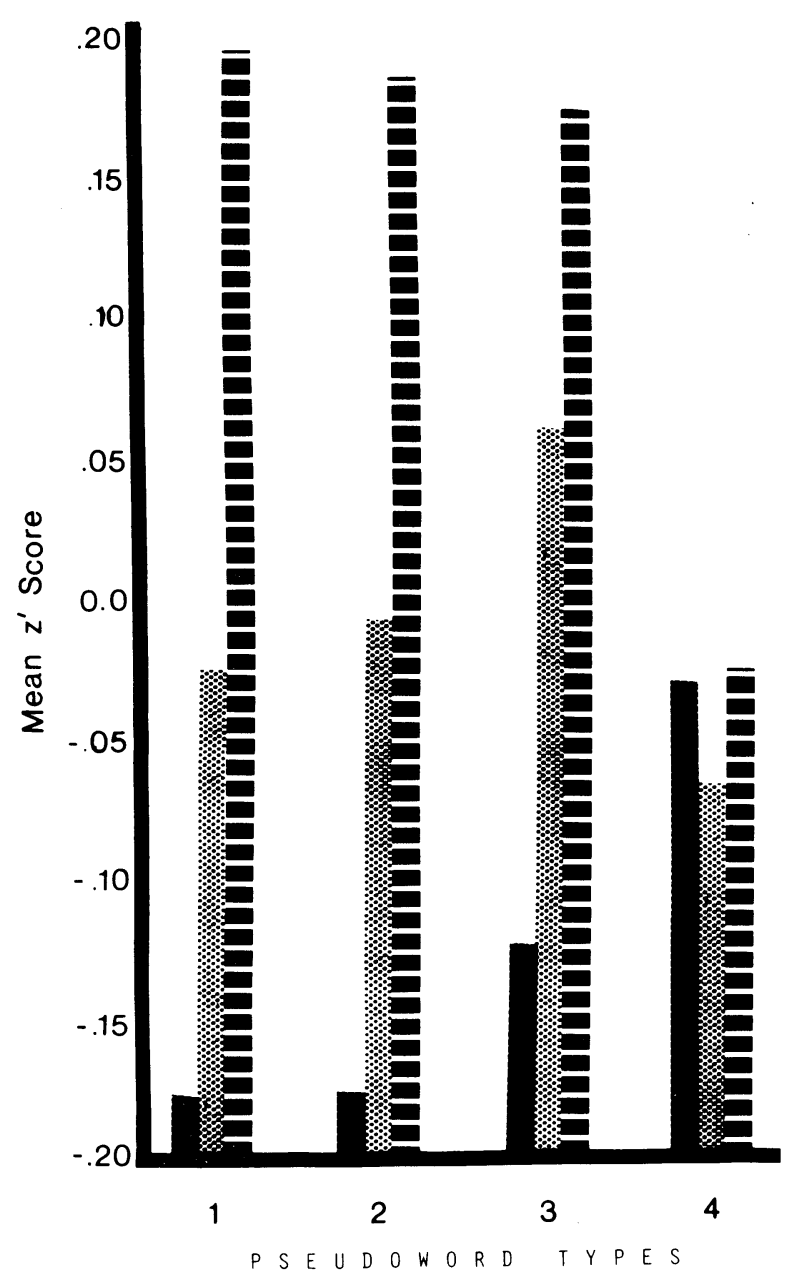

UPPER CASE - MIXED CASE

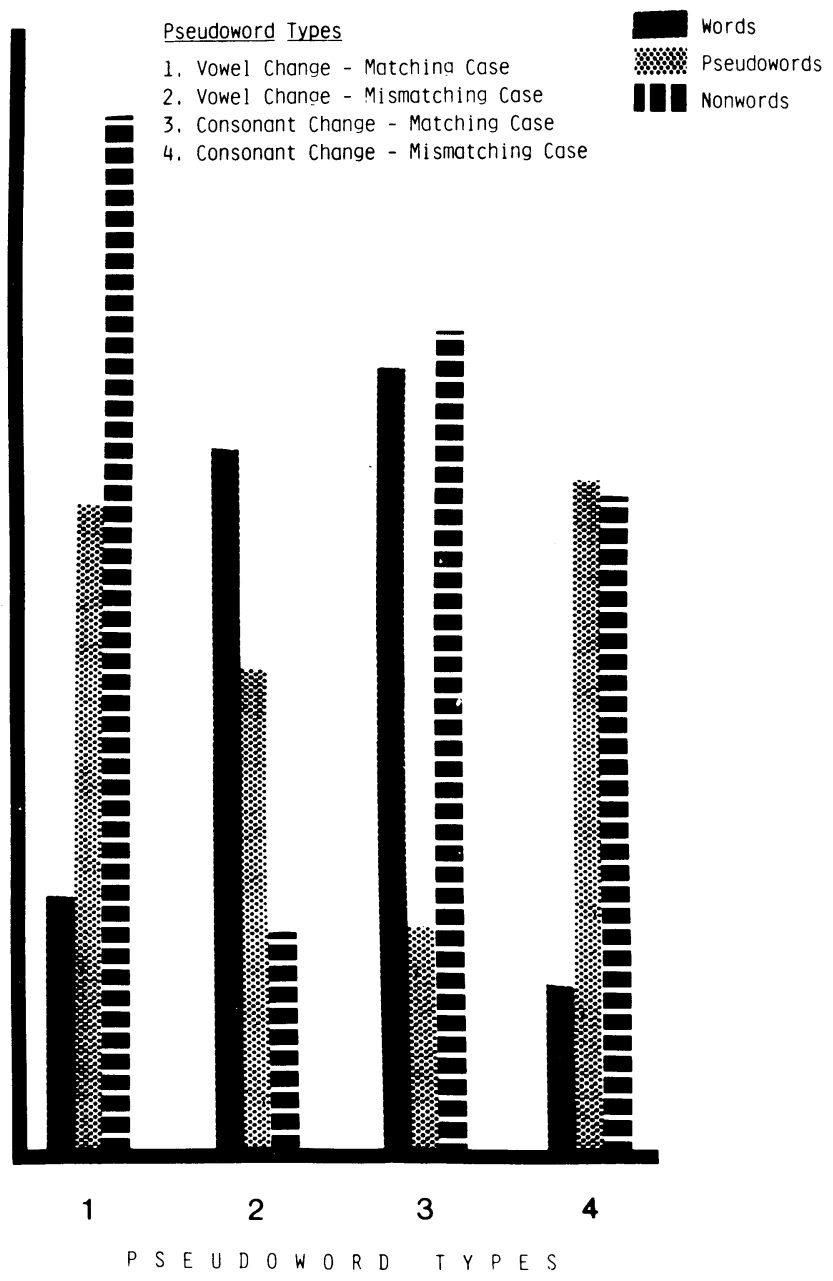

LOWER CASE - MIXED CASE

Figure 2. Mean $\mathrm{z}^{\prime}$ scores for Word, Pseudoword, and Nonword stimulus pairs for each type of Pseudoword and each arrangement of Matching and Mismatching letter case in Experiment 3.

\section{EXPERIMENT 4}

The last question concerns recognizability of stimulus inputs under the conditions of Experiments 2 and 3. Recall that exposure duration for these experiments was $11 \mathrm{msec}$ less than the average duration for chance-level letter case discriminations in Experiment 1, and they were both preand postmasked. Experiment 4 presented a forced-choice test of recognition of the stimulus materials of the first three experiments under the viewing conditions of Experiments 2 and 3 .

\section{Method}

Subjects. Forty volunteers from undergraduate psychology courses at Iowa State University participated for course credit. All subjects had normal or corrected-to-normal vision.

Stimulus materials. Stimulus pairs were selected from the materials used in Experiments 1, 2, and 3. The following seven relationships between pairs of letter strings were used: (1) the same word in both rows, (2) two synonymous words, (3) two words with different meanings, (4) a word and a low spatial frequency redundancy nonword, (5) two pseudowords produced by changing the positions of vowels in words, (6) two pseudowords produced by changing the positions of consonants in words, and (7) two nonwords of low spatial frequency redundancy. Arrangement of matching upper case pairs, matching lower case pairs, and mismatching case pairs were the same as in Experiments 2 and 3. Examples of these materials are shown in Table 7. Four different sets of exemplars of the seven relationships shown in Table 7 were selected. The 40 subjects were randomly assigned to eight groups of 5 subjects each, and materials for each of these groups were the seven relationships between stimulus pairs presented in one of the eight combinations of four exemplars and two types of matching (upperlower) and mismatching case pairs. Thus, the stimulus set for a given subject consisted of 14 pairs: seven pair relationships presented in matching and seven presented in mismatching letter case pairs. Exposure durations were $30 \mathrm{msec}$, and test presentations were preand postmasked by the mask of overlaid Xs and Os. Light levels in the tachistoscope were the same as for the previous experiments.

Procedure and design. On each trial, the subject viewed a $30 \mathrm{msec}$ test slide presentation, and was then asked which of two slides (the test slide and another member of the set) presented out- 
Table 7

Illustrative Stimulus Pairs: Experiment 4

\begin{tabular}{|c|c|c|c|c|c|c|}
\hline Same Word & Synonyms & $\begin{array}{l}\text { Different } \\
\text { Words }\end{array}$ & $\begin{array}{l}\text { Word + Low } \\
\text { SFR Nonword }\end{array}$ & $\begin{array}{l}\text { Pseudowords } \\
\text { (Vowel Change) }\end{array}$ & $\begin{array}{l}\text { Pseudoword } \\
\text { (Consonant Change) }\end{array}$ & $\begin{array}{l}\text { Low SFR } \\
\text { Nonwords }\end{array}$ \\
\hline \multicolumn{7}{|c|}{ Upper Case } \\
\hline MALLET & MALLET & CHAIR & MALLET & CHIAR & TAMELL & ICHRA \\
\hline MALLET & HAMMER & MALLET & NVEBIO & MELLAT & NAIRT & EMLLTA \\
\hline \multicolumn{7}{|c|}{ Lower Case } \\
\hline $\begin{array}{l}\text { bovine } \\
\text { bovine }\end{array}$ & $\begin{array}{l}\text { bovine } \\
\text { cattle }\end{array}$ & $\begin{array}{l}\text { train } \\
\text { bovine }\end{array}$ & $\begin{array}{l}\text { bovine } \\
\text { ichra }\end{array}$ & $\begin{array}{l}\text { trian } \\
\text { bevoni }\end{array}$ & $\begin{array}{l}\text { raich } \\
\text { nobive }\end{array}$ & $\begin{array}{l}\text { rntai } \\
\text { nvebio }\end{array}$ \\
\hline \multicolumn{7}{|c|}{ Mismatching Case } \\
\hline $\begin{array}{l}\text { CHAIR } \\
\text { chair }\end{array}$ & $\begin{array}{l}\text { chair } \\
\text { SEAT }\end{array}$ & $\begin{array}{l}\text { CHAIR } \\
\text { bovine }\end{array}$ & $\begin{array}{l}\text { chair } \\
\text { RNTAI }\end{array}$ & $\begin{array}{l}\text { CHIAR } \\
\text { bevoni }\end{array}$ & $\begin{array}{l}\text { raich } \\
\text { TAMELL }\end{array}$ & $\begin{array}{l}\text { ichra } \\
\text { NVEBIO }\end{array}$ \\
\hline
\end{tabular}

side the tachistoscope on a back-lighted viewing box was the slide presented on that trial. Thus, the test was a forced choice new-old recognition test for each test slide. To approximate the number of trials (60) of the duration judgment task of Experiments 2 and 3, each subject was tested over four independently randomized replications of the 14 slides of his/her set ( 56 trials per subject). The performance measure was the number of recognition errors in each of the four replications.

\section{Results}

The hypothesis that subjects did not recognize stimulus inputs in Experiments 2 and 3 prompts four expectations of the data from Experiment 4.

First, chance expectation for the forced choice test would be that, averaged across subjects, mean number of errors on 56 trials would be 28 . The observed mean was 27.33, and a $t=.97$ showed that expected and observed means did not differ.

Second, recognition errors for the various test stimuli should show no effect of the manipulated variables. An analysis of variance applied to error scores evaluated effects of (1) type of matching case (i.e., upper case matching plus mismatching case pairs vs. lower case matching plus mismatching case pairs), and (2) exemplar set as between-subjects variables; and (1) matching versus mismatching letter case and (2) the seven relationships between pair members as within-subject factors. None of the $15 \mathrm{~F}$ tests of that analysis even approached statistical significance.

Third, the number of times each stimulus was selected in an error choice when it served as a lure should show no effects of the manipulated variables. This analysis evaluated the same factors as the first analysis, and the result was the same; none of the $F$ tests approached significance. This result shows that there were no consistent response biases in error choices.

Fourth, the number of recognition errors should not change across replications. The measures for the above two analyses were obtained by adding errors over replications; the measure used to test the effect of replications was obtained by adding number of errors over the 14 stimuli in each replication. The analysis evaluated the same between-subject factors as before, but the withinsubject factor was replications. The result was as expected; no significant $F$ values were obtained.
Thus, while positive statements must be made with caution when null hypotheses cannot be rejected, the combined results of all analyses performed on the data from Experiment 4 are in accord with the hypothesis that the viewing conditions of Experiments 2 and 3 did not permit subjects a visible image of the display.

\section{GENERAL DISCUSSION}

Results of these experiments support the following conclusions. The results of Experiment 1 confirm the indication from Fowler et al. (1981), Marcel (1983b) and Merikle (1982) that tasks which require a direct forcedchoice identification response to stimulus inputs are not well suited for distinguishing between unconscious use of input information and response biases. Tests of unconscious use of letter case, lexical, and meaning information in Experiment 1 followed a threshold setting procedure that met Merikle's criteria for discriminating between conscious and unconscious processing but failed to distinguish between unconscious use of these types of information and a preference for Same responses.

Although it presents the subject an unusual task, the duration judgment paradigm is better suited for revealing the unconscious operations that precede recognition. With pre- and postmasked exposure durations briefer than the average duration for chance-level case discriminations in Experiment 1, Experiments 2 and 3 made several salient points. The results of Experiment 2 can be used to argue that (a) the processing indexed by this task is directed by information extracted during the two stimulus flashes of each trial, and (b) that both letter case and lexical/semantic information are accessed and used when neither type of information is available to conscious perception. Consideration of the sequence of events leading to the duration judgment suggests that both an analytic and a storage operation for each type of information (with an implied retrieval, recovery, or transformation operation) must have preceded the duration judgment. The results of Experiment 3 identified separable effects of letter case, orthographic regularity, and semantic information in early processing and suggested that, while all three types of information are initially analyzed, the higher order lexical information gains priority in determining the conscious 
perception as processing approaches its terminus in a stabilized percept. Finally, the results of Experiment 4 leave little doubt that the processing evident in Experiments 2 and 3 occurred without a visible image of the display and completely outside of the subject's awareness.

In our view, the duration judgment data bring several theoretical issues into clearer focus. Specifically, the data permit clarification of three distinctions: conscious versus unconscious processing, automatic versus intentionally or attentionally guided processing, and the relationship between masking stimuli and the prerecognition operations that produce current perceptual awareness.

\section{Conscious versus Unconscious Processing}

In current two-process models (e.g., Collins \& Loftus, 1975; LaBerge \& Samuels, 1974; Posner \& Snyder, 1975; Shiffrin \& Schneider, 1977), the unconscious-conscious dichotomy is closely allied with the automaticnonautomatic distinction. Limited capacity conscious processing is associated with allocation of attentional resources and unconscious processing involves automatic access to the memory structure.

Data from the duration judgment paradigm address the unconscious-conscious distinction and the automaticity question separately. One clear indication of these data is that conscious awareness need not be the same as any one or combination of the types of information that were unconsciously analyzed. The duration judgment paradigm puts the subject in a very unusual situation for processing verbal materials; one of its unique advantages is the qualitative difference between the format of the requested report and the format of the manipulated parameters that influence the report. Consideration of the sequence of events on each trial suggests that some operation communicates the residuals of incomplete processing of verbal parameters to a conscious mechanism in the form of temporal extents; apparently that communication operation occurs twice on each trial before a comparison and decision are made. The link between unconscious and conscious processing must surely be more than a duplication in consciousness of the formats of unconsciously processed information (cf. Corteen \& Wood, 1972; Weiskrantz, Warrington, Sanders, \& Marshall, 1974).

\section{Automatic versus Attentionally Guided Processing}

The data address the question of automatic versus attentionally guided processing separated from the question of unconscious versus conscious processing. The point is that some processing that appears to be automatic may not be free of intentional or attentional guidance (see, e.g., Neumann, 1984; Underwood, 1982). An example is provided by studies using the semantic priming paradigm (e.g., Balota, 1983; Fowler et al., 1981; Marcel, 1983b; Neely, 1977). For that task, Neumann (1984) notes that task instructions set an intent to process verbal materials; he then distinguishes between the effect of the prime stimulus and the subsequent processing of the target (also see Broadbent, 1982). He suggests that the prime stimu- lus sets a state of readiness for subsequent uptake and evaluation of the target stimulus information ("processing proper'); automaticity is associated with the state of readiness set by the prime stimulus-preparation that facilitates processing if it can be used but may not hinder processing if it cannot (e.g., Neely, 1977). To the extent that it is guided by task instructions and the state of readiness, "processing proper" of the target is not automatic.

The duration judgment data present an example of verbal/linguistic processing that is apparently automatic, unavoidable, and independent of attention or "state of readiness." For this task, the subject's state of readiness is set for temporal processing, thus establishing a particular intent that does not incorporate an unconsciously maintained state of readiness to process verbal materials. Yet, when such materials are presented, the subject appears to automatically, unconsciously, and unavoidably process several verbal/linguistic parameters of the input and then recode the format(s) of those materials into a subjective temporal format. The data appear to reflect the operation of long-standing verbal skills that are automatically and unavoidably called for and specified by particular stimulus parameters, and this occurs without any guidance from a state of readiness to process in a verbal domain.

\section{Central Pattern Masking}

The relationship between central pattern masking and the types of information that enter current awareness is also addressed by these data. The theoretical context in which that relationship is most productively addressed is afforded by the similar models offered by Allport (1977, 1979), Coltheart (1980), and Marcel (1983a). Marcel's is the most thoroughly elaborated of these models. Marcel's intent is a detailed account of the means whereby input information is unconsciously analyzed and subsequently brought into consciousness. Much of the force of Marcel's proposals originates in his rejection of the "Identity Assumption," the assumption that "the representations which constitute conscious experience are. . the same ones that are derived from and used in sensory and cognitive processing"' (p. 238). With that assumption rejected, Marcel develops the thesis that conscious perception resides in structural descriptions (Hochberg, 1970) that express the conscious attempt to make as much sense as possible out of as much data as possible at the highest order and most functionally useful level permitted by the input.

Distilled to its essential components, Marcel's argument is as follows. All sensory inputs, no matter how briefly registered at the sensory surface, are automatically and unconsciously analyzed, by multiple specialist processing operations, into every representational format that is maintained in the memory structure. Products of these analyses have two important aspects, their results and their records. Results provide input and materials to numerous other unconscious operations that can use them, and they suggest candidate perceptual hypotheses. Records provide the basis of the form and content of conscious 
percepts. Perceptual hypotheses are analogous to Minsky's (1975) concept of "frames" and to Rumelhart's (1978) "schemata," and they are the mechanisms of conscious percepts.

Synthesis of a conscious perception requires matching a candidate hypothesis against sensory data, so the relevant data must be recovered. The recovery process (a) is guided by the conscious need to make as much sense as possible of the input, (b) proceeds from higher, more abstract levels to lower levels (consistent with our learning to perceive the significance of inputs rather than the cues to their significance) and, as in Kolers's (1962) clerkcustomer analogy, recovery of a record or a subset of records is bounded by interference. Central pattern masking is a structural aspect of the recovery process. The most recent or spatially proximal records may capture recovery and gain figural status. Alternatively, the set of elements which corresponds to a more economical or higher level description, or a more expected event, will be privileged in recovery.

The data from Experiments 2 and 3 conform parsimoniously to these proposals. They clearly indicate that letter case, orthographic regularity, and lexical/semantic information were analyzed. Given the viewing conditions and the subjects' instructions to process temporal information, there is good reason to believe that anlysis of verbal/linguistic information occurred automatically, unavoidably, and outside of the subject's awareness. And, the sequence of events on each trial required that some record(s) of those analyses be stored and recovered to guide the duration judgment. The format of the conscious report had to result from a transformation of the analyzed input in order to conform to the subject's expectation that flash durations would vary. The predominance of lexi$\mathrm{cal} / \mathrm{semantic}$ information over letter case information and the fact that these judgments were obtained with brief and severely pre- and postmasked inputs permit two inferences. Subjects appear to have adapted to the task requirement by testing perceptual hypotheses that would justify a temporal rather than verbal/linguistic judgment. And, it appears that they accomplished that adaptation by recovering a high level abstract form of information: the difference in subjective time invested in analyzing words and nonwords. Apparently, records of the featural analysis of letters (recovery of which is necessary for conscious visible synthesis of the letter strings) were destroyed by the pattern mask whereas the abstract temporal record of the time spent in unconscious automatic analysis was not vulnerable to erasure by the visible features of the mask.

We believe that the distinctions between (1) analyses and recovery and (2) results and records of unconscious analyses are important; the present data seem to require the differentiation. It seems clear that rather thorough unconscious analyses are performed; the need to empirically delineate the recovery process remains. In recognizing that need, Marcel echoes Turvey (1974) in noting that "The Hoffding step (Hoffding, 1891) remains very much a mystery."

\section{REFERENCES}

ALLPORT, D. A. (1977). On knowing the meaning of words we are unable to report: The effects of visual masking. In S. Dornic (Ed.), $A t-$ tention and Performance IV. Hillsdale, NJ: Erlbaum.

ALLPORT, D. A. (1979). Word recognition in reading. In P. A. Kolers, M. E. Wrolstad, \& H. Bouma (Eds.), Processing of visible language Volume 1. New York: Plenum Press.

Avant, L. L., Bartsch, T. M., \& Woods, A. T. (1977, November). Signal detection and duration judgment as indicators of early visual processes: $d^{\prime}$ and $z^{\prime}$. Paper presented at the meeting of The Psychonomic Society, Washington, D. C.

Avant, L. L., \& Lyman, P. J. (1975). Stimulus familiarity modifies perceived duration in prerecognition visual processing. Journal of Experimental Psychology: Human Perception \& Performance, 1, 205-213.

Avant, L. L., Lyman, P. J., \& ANTEs, J. R. (1975). Effects of stimulus familiarity upon judged visual duration. Perception \& Psychophysics, 17, 253-262.

Avant, L. L., Lyman, P. J., Skowronski, M., \& Millspaugh, J. R. (1977). Perceived tachistoscopic duration and early visual processing in preschool children and adults. Journal of Experimental Child Psvchology, 23, 348-366.

Avant, L. L., Mineck, D., \& Favale, T. (1984, November). Prerecognition processing of words and nonwords by left and right hemispheres. Paper presented at the meeting of The Psychonomic Society, San Antonio.

Balota, D. A. (1983). Automatic semantic activation and episodic memory encoding. Journal of Verbal Learning \& Verbal Behavior, 22, 88-104.

Baron, J. (1975). Successive stages in word recognition. In P. M. A. Rabbitt \& S. Dornic (Eds.), Attention and Performance V. New York: Academic Press.

Baron, J., \& Thurston, I. (1973). An analysis of the word-superiority effect. Cognitive Psychology, 4, 207-228.

BRoAdBent, D. E. (1982). Task combinations and selective intake of information. Acta Psychologia, 50, 253-290.

Collins, A. M., \& Lofius, E. F. (1975). A spreading-activation theory of semantic processing. Psychological Review, 82, 407-428.

Coltheart, M. (1980). Iconic memory and visible persistence. Perception \& Psychophysics, 27, 183-228.

CorteEn, R. S., \& WoOD, B. (1972). Autonomic responses to shockassociated words in an unattended channel. Journal of Experimental Psychology, 94, 308-313.

Estes, W. K., Allmeyer, D. H., \& Reder, S. (1976). Serial position functions for letter identification at brief and extended exposure durations. Perception \& Psychophysics, 19, 1-15.

Fowler, C. A., Wolford, G., Slade, R., \& Tassinary, L. (1981). Lexical access with and without awareness. Journal of Experimental Psychology: General, 110, 341-362.

FRIEDMAN, R. B. (1980). Identity without form: Abstract representations of letters. Perception \& Psychophysics, 28, 53-60.

HABER, R. N. (1969). Repetition as a determinant of perceptual recognition processes. In R. N. Haber (Ed.), Information-processing approaches to visual perception. New York: Holt, Rinehart, \& Winston.

Hirata, K. \& Bryden, M. (1971). Tables of letter sequences varying in order of approximation to English. Psychonomic Science, 25, 322-324.

HoCHBERG, J. (1970). Attention, organization, and consciousness. In D. I. Mostofsky (Ed.), Attention: Contemporary theory and analysis. New York: Appleton-Century-Crofts.

HoffDing, H. (1891). Outlines of psychology. New York: MacMillan. Huber, S. J., \& JoHnson, N. F. (1980, May). The role of iconic imagery in visual information processing. Paper presented at the meeting of the Midwestern Psychological Association, Saint Louis.

Kolers, P. A. (1962). Intensity and contour effects in visual masking. Vision Research, 2, 277-294.

LABERGE, D., \& SAMUELS, S. J. (1974). Toward a theory of automatic information processing in reading. Cognitive Psychology, 6, 293-323.

MARCEL, A. J. (1980). Conscious and preconscious recognition of polysemous words: Locating the selective effects of prior verbal context. 
In R. S. Nickerson (Ed.), Attention and Performance VIII. Hillsdale, NJ: Erlbaum

Marcel, A. J. (1983a). Conscious and unconscious perception: An approach to the relations between phenomenal experience and perceptual processes. Cognitive Psychology, 15, 238-300.

MARCEL, A. J. (1983b). Conscious and unconscious perception: Experiments on visual masking and word recognition. Cognitive Psychology, 15, 197-237.

Marcel, A. J., \& Patterson, K. E. (1978). Word recognition and production: Reciprocity in clinical and normal studies. In J. Requin (Ed.), Attention and Performance VII. Hillsdale, NJ: Erlbaum.

MAson, M. (1975). Reading ability and letter search time: Effects of orthographic structure defined by single-letter positional frequency. Journal of Experimental Psychology: General, 104, 146-166.

Massaro, D. W. (1973). Perception of letters, words, and nonwords. Journal of Experimental Psychology, 100, 349-353.

MASSARO, D. W. (1975). Understanding language: An informationprocessing analysis of speech perception, reading, and psycholinguistics. New York: Academic Press.

Mayzner, M. S., \& Tresselt, M. E. (1965). Tables of single-letter and digram frequency counts for various word-length and letter position combinations. Psychonomic Monograph Supplements, 1, 13-32.

MerikLE, P. M. (1982). Unconscious perception revisited. Perception \& Psychophysics, 31, 298-301.

Minsky, M. (1975). A framework for representing knowledge. In P. A. Winston (Ed.), The psychology of computer vision. New York: McGraw-Hill.

NeELy, J. H. (1977). Semantic priming and retrieval from lexical memory: Roles of inhibitionless spreading activation and limited capacity attention. Journal of Experimental Psychology: General, 106 , 226-254.

NeUmanN, O. (1984). Automatic processing: A review of recent findings and a plea for an old theory. In W. Prinz \& A. F. Sanders (Eds.), Cognition and motor processes. Berlin: Springer-Verlag.

Nolan, K. A., \& CaramazzA, A. (1982). Unconscious perception of meaning: A failure to replicate. Bulletin of the Psychonomic Society, 20, 23-26.
Posner, M. I., \& Snyder, C. R. R. (1975). Attention and cognitive control. In R. L. Solso (Ed.), Information processing and cognition: The Loyola symposium. Hillsdale, $\mathrm{NJ}$ : Erlbaum.

Rumelhart, D. E. (1978). Schemata: The building blocks of cognition. In R. Spiro, B. Bruce, \& W. Brewer (Eds.), Theoretical issues in reading comprehension. Hillsdale, $\mathrm{NJ}$ : Erlbaum.

SHIFFrin, R. M., \& SCHNEIDER, W. (1977). Controlled and automatic information processing: II. Perceptual learning, automatic attending, and a general theory. Psychological Review, 84, 127-190.

SNODGRASS, J. G., \& VANDERWART, M. (1980). A standardized set of 260 pictures: Norms for name agreement, image agreement, familiarity, and visual complexity. Journal of Experimental Psychology: Human Learning \& Memory, 6, 174-215.

Turvey, M. T. (1974). Constructive theory, perceptual systems, and tacit knowledge. In W. B. Weimer \& D. S. Palermo (Eds.), Cognition and the symbolic processes. Hillsdale, $\mathrm{NJ}$ : Erlbaum.

TURVEY, M. T. (1978). Visual processing and short-term memory. In W. K. Estes (Ed.), Handbook of learning and cognitive processes Volume 5. Hillsdale, NJ: Erlbaum.

UNDERWOOD, G. (1982). Aftention and awareness in cognitive and motor skills. In G. Underwood (Ed.), Aspects of consciousness. Vol. 3. New York: Academic Press.

VENESKY, R. L. (1967). English orthography: Its graphical structure and its relation to sound. Reading Research Quarterly, 2, 75-106.

VENESKY, R. L. (1970). The structure of English orthography. The Hague: Mouton \& Co.

VENESKY, R. L., \& MASSARo, D. W. (1979). The role of orthographic regularity in word recognition. In L. B. Resnick \& P. A. Weaver (Eds.), Theory and practice of early reading Volume 1. Hillsdale, NJ: Erlbaum.

Webster's New Collegiate Dictionary. (1973). Springfield, MS: G \& C Merriam.

Weiskrantz, C., Warrington, E. K., Sanders, M. D., \& Marshall, J. (1974). Visual capacity in the hemianopic field following a restricted occipital ablation. Brain, 97, 709-728.

WOODWORTH, R. S. , \& SCH LOSBERG, H. (1954). Experimental psychology (Rev. ed.). New York: Holt, Rinehart, \& Winston

(Manuscript received September 21, 1984; revision accepted for publication May 30, 1985.) 